\title{
BMJ Open Trends in the prevalence, incidence and surgical management of carpal tunnel syndrome between 1993 and 2013: an observational analysis of UK primary
} care records

\author{
Claire L Burton, Ying Chen, Linda S Chesterton, Danielle A van der Windt
}

To cite: Burton CL, Chen Y, Chesterton LS, et al. Trends in the prevalence, incidence and surgical management of carpal tunnel syndrome between 1993 and 2013: an observational analysis of UK primary care records. BMJ Open 2018;8:e020166. doi:10.1136/ bmjopen-2017-020166

- Prepublication history and additional material for this paper are available online. To view these files, please visit the journal online (http://dx.doi. org/10.1136/bmjopen-2017020166).

Received 18 0ctober 2017 Revised 24 April 2018 Accepted 14 May 2018
Check for updates

Arthritis Research UK Primary Care Centre, Research Institute for Primary Care \& Health Sciences, Keele University, Staffordshire, UK

Correspondence to

Dr Claire L Burton;

c.burton@keele.ac.uk

\section{ABSTRACT}

Objectives To describe the prevalence, incidence and surgical management of carpal tunnel syndrome (CTS), between 1993 and 2013, as recorded in the Clinical Practice Research Datalink (CPRD).

Design We completed a series of cross-sectional epidemiological analyses to observe trends over time.

Setting Primary care data collected between 1993 and 2013, stored in the CPRD.

Population Individuals aged $\geq 18$ years were selected. Prevalent and incident episodes of CTS and episodes of surgical intervention were identified using a list of preidentified Read codes.

Analysis We defined incident episodes as those with no preceding diagnostic code for CTS in the past 2 years of data. Episodes of surgery were expressed as a percentage of the prevalent population during the same calendar year. Joinpoint regression was used to determine significant changes in the underlying trend.

Results The prevalence of CTS increased over the study period, with a particular incline between 2000 and 2004 (annual percentage change 7.81). The female-to-male prevalence ratio reduced over time from 2.74 in 1993 to 1.93 in 2013. The median age of females and males with CTS were noted to increase from 49 and 53 years, respectively in 1993 to 54 and 59 years, respectively in 2013. Incidence was also noted to increase over time. After an initial increase between 1993 and 2007, the percentage of prevalent patients with a coded surgical episode began to decrease after 2007 to $27.41 \%$ in 2013 (annual percentage change -1.7).

Conclusion This study has demonstrated that the prevalence and incidence of CTS increased over the study period between 1993 and 2013. Rates of surgery for CTS also increased over the study period; however after 2007, the per cent of patients receiving surgery showed a statistically significant decline back to the rate seen in 2004.

\section{INTRODUCTION}

Carpal tunnel syndrome (CTS) is a chronic focal compressive neuropathy caused by the entrapment of the median nerve at the level
Strengths and limitations of this study

- Provides updated epidemiological data about a common and bothersome condition.

- Set in primary care, where most cases of carpal tunnel syndrome present.

- Uses a large primary care database, generalisable to the UK population.

- Relies on the correct coding and capture of episodes of carpal tunnel syndrome and carpal tunnel release surgery.

of the carpal tunnel in the wrist. ${ }^{1}$ CTS is the most common presentation of the entrapment neuropathies ${ }^{2}$ and is characterised by symptoms including paraesthesia, dysesthesia, sensory loss and eventually weakness and atrophy of the thenar muscle. Symptoms are usually localised to the hand but can spread proximally to the forearm, upper arm and even shoulder. ${ }^{3}$ Despite causing relatively localised symptoms, CTS can have substantial physical, psychological and economic consequences. ${ }^{45}$ In some cases, there may be associations with certain occupations (such as the care and leisure industry), ${ }^{6}$ which involve the overuse of the hand and wrist as well as other physical comorbidities including pregnancy, diabetes, hypothyroidism and obesity. ${ }^{7}$

The diagnosis of CTS is generally accepted to be a clinical one (based on history and examination findings), ${ }^{8}$ although electrodiagnostic tests are commonly requested to confirm the diagnosis or differentiate among diagnoses, especially in the presence of thenar atrophy and/or persistent numbness or if surgical management is being considered. ${ }^{9}$ The treatment of CTS is usually defined as either surgical or conservative (non-surgical). Local steroid injections and night splinting form the mainstay of primary 
care interventions in CTS, as indicated by national care pathways. ${ }^{1011}$ Patients with moderate, severe or deteriorating symptoms following conservative treatment or sudden and severe symptoms are recommended to be referred for consideration of surgery. ${ }^{12}$ Carpal tunnel release surgery (CTR) is routinely carried out under local anaesthetic as day surgery. Open and endoscopic approaches are used to release the flexor retinaculum. ${ }^{13}$ Previous studies have sought to estimate the prevalence and/orincidence of CTS. Such epidemiological studies have been diverse in their approach to the populations studied and case definitions applied. ${ }^{14}$ The reported estimates for annual prevalence range from 3720 to 5700 per 100000 per year ${ }^{15-17}$ and the reported incidence from 72 to 8200 per 100000 per year. ${ }^{6}{ }^{18-23}$ CTS is generally accepted to be more common in women; the female-tomale ratio ranges between 0.78 and $9.66 .{ }^{14}{ }^{15}$ A number of previous studies have observed the trends of prevalence or incidence over time and identified an increase,,${ }^{19} 2024$ with 2005 being the latest data collection point. The most recent primary care-based study in the UK used data between 1992 and 2000. ${ }^{18}$

Episodes of CTR have also been shown to have increased, with audit data from one major tertiary UK Hand Centre suggesting that referral for CTR increased over a 10-year period from 59.7 to 112 per 100000 population per year between $1989-1999$ and $2000-2001 .{ }^{25}$ Using Hospital Episode Statistics (HES) between 1998 and 2011, Bebbington and Furniss also observed an increase in the absolute number of patients with CTS and episodes of CTR; however, they also noted a decrease in the use of surgery post-2008. ${ }^{26}$

Previous studies have used a range of methods to classify episodes of CTS and have been conducted in a number of population settings. CTS is essentially a clinical diagnosis, and in the UK, the majority of patients will first present to and be managed within primary care. Only a proportion of these patients will be referred into more specialised services and since not all surgical episodes will take place in secondary care (hospitals), as community clinics are now receiving referrals, primary care records should capture the majority of episodes. Data from a high-quality source, representative of the UK population is necessary to support the planning and commissioning of services.

The aim of this study is therefore to provide updated estimates of the prevalence, incidence and surgical management of CTS and describe trends over a 20-year period, using data from a large national primary care database (Clinical Practice Research Datalink (CPRD)).

\section{METHODS}

This was an observational study using the CPRD to estimate the prevalence, incidence and surgical management of CTS from 1993 to 2013. CPRD is a live, primary care database of anonymised medical records from general practices. It holds information of over 11.3 million patients from 674 practices in the UK since 1987; 4 .4 million active
Table 1 Read codes used to define a prevalent or incident episode of carpal tunnel syndrome

\begin{tabular}{ll}
\hline Term & Read code \\
\hline Carpal tunnel syndrome & F340 \\
\hline Injection of carpal tunnel & $85 B E .00$ \\
Carpal tunnel release & 70560 \\
$\begin{array}{ll}\text { Endoscopic carpal tunnel } \\
\text { release }\end{array}$ & 7056011 \\
Carpal tunnel decompression & 70564
\end{tabular}

(alive and currently registered) patients are currently contributing information to the datalink, which equates to $6.9 \%$ of the UK population. ${ }^{27}$ The CPRD is broadly representative of the UK general population in terms of age, gender and ethnicity. ${ }^{27}$ The CPRD has National Research Ethics Committee approval for observational research using primary care data and as such no further permissions were required. The Independent Scientific Advisory Committee study protocol 14_167 was approved in September 2014.

During clinical interactions, Read codes are used to record signs and symptoms, treatments and therapies, investigations, occupations, diagnoses and appliances. Read codes make up a hierarchical 'thesaurus' stored by the computer. Clinical information is hence stored in a retrievable and analysable format. ${ }^{28}$

The study population consisted of men and women over 18 years of age. Data was used from practices which met a data quality standard based on continuity of recorded data, and from patients who had a record including at least their registration status, age and gender. These quality standards were required to have been met for at least 2 years prior to an incident episode and at the point of diagnosis for a prevalent episode. ${ }^{27}$

Prevalent and incident patients were identified by a consultation recorded using one of the Read codes listed in table 1 . Some treatment codes and in the case of in injections, linked prescription data, were included as evidence of diagnosis as per previous studies. ${ }^{18}$ Pilot work using a local primary care database (Consultations in Primary Care Archive (CiPCA $)^{29}$ ) had noted that $30 \%$ of CTS cases with a treatment code (ie, CTR or a coded carpal tunnel injection) had not initially received a diagnosis code. This means that at presentation, patients may have been attributed a more generic term such as 'hand pain' and later gone on to receive condition-specific treatment. Hence, treatment codes were used to capture such cases, which would be missed when using diagnostic codes only.

The prevalence of individuals consulting with CTS was calculated per annum. The numerator for prevalence was the number of patients with a record of a CTS diagnosis or evidence of an episode of CTR or a carpal tunnel injection (CTI), in each calendar year. In order to determine annual incidence, the numerator was the 
number of patients with a record of CTS or evidence of CTR or CTI, without a prior record of these codes during a run-in period of 2 years. This 2-year run-in period was based on expert consensus with the aim of estimating the period of time during which a new episode of CTS may develop. It was felt unlikely that a patient with ongoing bothersome symptoms would not have presented in primary care within this 2-year period. This however is an assumption made in order to define incident cases in this data set. It remains possible that patients had CTS in the community and did not present, presented in an alternative setting or indeed had a misdiagnosis/uncoded diagnosis made. CTS could present as a new episode in the contralateral wrist sometime after the initial presentation, hence it was not felt possible to define this criterion as 'no previous recorded episode'. All incidence patients were therefore required to have complete registration for this two calendar years prior to the event date. Pilot work in CiPCA had shown that over 9 years observed, $4 \%$ of potential incident cases were lost due to the lack of 2 years registration data required to define an incident episode.

The denominator population for calculation of prevalence was the total up-to-standard person-years contributed to CPRD by patients over the age of 18 years, for each annual period between 1993 and 2013. In order to apply the same criteria to both the numerator and denominator populations, the denominator populations for calculating incidence were also required to have registration at the mid-point of the year, two calendar years before the index year.

Episodes of CTR were identified using Read codes as shown in table 2. In addition, codes used to define 'rerelease of carpal tunnel' and 'revision of carpal tunnel release' were included as a surgical episode (if first recorded). These terms were not included in the definition of CTS for the estimation of prevalence and incidence as they may not have indicated an episode of 'idiopathic' CTS but rather iatrogenic symptoms following previous (unsuccessful) surgery. Of note, revision codes contributed $1.00 \%$ of the total surgical codes used. Results were expressed as the percentage of patients with a prevalent episode of CTS having a code of CTR in the same calendar year. Percentages were calculated based on the number of prevalent cases as opposed to incident cases as

\begin{tabular}{lc}
\hline Table 2 & Read codes used to define a surgical episode \\
\hline Term & Read code \\
\hline $\begin{array}{lc}\text { Carpal tunnel release } \\
\text { Rerelease of carpal tunnel }\end{array}$ & 16896 \\
$\begin{array}{l}\text { Endoscopic carpal tunnel } \\
\text { release }\end{array}$ & 39335 \\
$\begin{array}{l}\text { Revision of carpal tunnel } \\
\text { release }\end{array}$ & 97195 \\
Carpal tunnel decompression & 19249
\end{tabular}

it was felt likely that patients would receive surgery in the annual period following their index consultation.

\section{Statistical methods}

Age-specific and sex-specific annual prevalence and incidence were determined for each calendar year, between 1993 and 2013 and presented as n/10000 person-years. For CI calculation a Poisson distribution was used. As a sensitivity analysis, age-standardised and sex-standardised annual figures of CTS prevalence and incidence for each year were also calculated, using population estimates provided by the website of the Office of National Statistics. ${ }^{30}$ Unstandardised and standardised rates were very similar, hence we report unstandardised rates as the primary outcome. The age-standardised and sex-standardised estimates of the annual prevalence and incidence of CTS are shown in online supplementary table 1.

Episodes of CTR were identified and the frequency in each calendar year expressed as a percentage of the prevalent population for the same time period. Emerging trends were described. Joinpoint regression was used to determine mean annual percentage change (APC) and assess when significant changes ('Joinpoints') occurred in the underlying trend for incidence, prevalence and surgery. This method assists the exploration of the potential influence of changes in practice, although such potential associations cannot be proven. ${ }^{31}{ }^{32}$ Models were fitted using the Joinpoint Regression Program (V.4.3.1.0) and the best fitting model chosen (up to five Joinpoints).

\section{Patient and public involvement}

Patients were not directly involved in the design of this study; however, the results will be used to inform discussions regarding further research in this field with our local Research User Group.

\section{RESULTS}

\section{Trends in prevalence}

Table 3 presents the prevalence (crude estimates) of patients presenting in primary care with CTS between 1993 and 2013 and the demographics of the population. The denominator population for prevalence increased from 1117433 person-years in 1993 to 3473094 personyears in 2013. The total prevalence in 1993 was 26.03 per 10000 person-years (95\% CI 25.10 to 27.00 ), and for 2013, 36.08 per 10000 person-years (95\% CI 35.45 to 36.72). As shown in figure 1 and corresponding table 4 , prevalence appeared to decrease between 1993 and 2000 $(\mathrm{APC}=-0.8 \%, 95 \%$ CI -2.6 to 1.0$)$. It then increased between 2000 and 2004 (APC=7.8\%, 95\% CI 3.1 to 12.7) and then increased at a slower rate between 2004 and 2013 (APC=1.1\%, 95\% CI 0.4 to 1.8). The female-to-male ratio reduced over time from 2.74 in 1993 to 1.93 in 2013. The median age of female and male patients with CTS increased from 49 and 53 years, respectively in 1993 to 54 and 59 years, respectively in 2013 (see online supplementary table 2). Online supplementary table 3 and 
Table 3 Crude prevalence of carpal tunnel syndrome ( $\mathrm{n} / 10000$ person-years) per calendar year, as presented in UK primary care (Clinical Practice Research Datalink)

\begin{tabular}{|c|c|c|c|c|c|c|}
\hline Year & $\begin{array}{l}\text { Number } \\
\text { of person- } \\
\text { years }\end{array}$ & $\begin{array}{l}\text { Prevalent } \\
\text { individuals }\end{array}$ & $\begin{array}{l}\text { Total crude prevalence } \\
\text { per } 10000 \text { person-years, } \\
(95 \% \mathrm{Cl})\end{array}$ & $\begin{array}{l}\text { Female prevalence per } \\
10000 \text { person-years, } \\
(95 \% \mathrm{Cl})\end{array}$ & $\begin{array}{l}\text { Male prevalence per } \\
10000 \text { person-years, } \\
(95 \% \mathrm{Cl})\end{array}$ & Female:male \\
\hline 1993 & 1117443 & 2909 & 26.03 (25.10 to 27.00$)$ & 37.52 (35.96 to 39.13 ) & $13.69(12.72$ to 14.71$)$ & 2.74 \\
\hline 1994 & 1198256 & 3188 & 26.61 (25.69 to 27.55 ) & 37.23 (35.73 to 38.79$)$ & 15.21 (14.23 to 16.25$)$ & 2.45 \\
\hline 1995 & 1286800 & 3343 & 25.98 (25.11 to 26.88 ) & 36.64 (35.20 to 38.12$)$ & 14.58 (13.65 to 15.56$)$ & 2.51 \\
\hline 1996 & 1437567 & 3706 & 25.78 (24.96 to 26.62$)$ & 36.75 (35.38 to 38.16$)$ & 14.09 (13.23 to 15.00$)$ & 2.61 \\
\hline 1997 & 1681756 & 4190 & 24.91 (24.17 to 25.68 ) & 34.87 (33.64 to 36.14$)$ & 14.34 (13.53 to 15.18$)$ & 2.43 \\
\hline 1998 & 1899393 & 4884 & 25.71 (25.00 to 26.45$)$ & 36.57 (35.38 to 37.79$)$ & $14.22(13.46$ to 15.01$)$ & 2.57 \\
\hline 1999 & 2289158 & 5696 & $24.8 \varepsilon$ & 35.2 & (13.32 to 14.72 ) & 2.52 \\
\hline 2000 & 2787457 & 6998 & 25.11 (24.52 to 25.70$)$ & 34.82 (33.86 to 35.81$)$ & 14.90 (14.26 to 15.57$)$ & 2.34 \\
\hline 2001 & 3057458 & 8137 & 26.61 (26.04 to 27.20$)$ & 36.46 (35.52 to 37.42$)$ & 16.31 (15.67 to 16.98$)$ & 2.23 \\
\hline 2002 & 3385511 & 9722 & $28.72(28.15$ to 29.29$)$ & 39.33 (38.40 to 40.28$)$ & $17.64(17.00$ to 18.29$)$ & 2.23 \\
\hline 2003 & 3552908 & 11124 & 31.31 (30.73 to 31.90$)$ & 43.61 (42.66 to 44.59 ) & $18.53(17.90$ to 19.18$)$ & 2.35 \\
\hline 2004 & 3712172 & 12622 & 34.00 (33.41 to 34.60$)$ & 47.20 (46.23 to 48.19$)$ & 20.33 (19.68 to 20.99) & 2.32 \\
\hline 2005 & 3808183 & 12741 & 33.46 (32.88 to 34.04$)$ & $46.37(45.42$ to 47.34$)$ & 20.09 (19.45 to 20.74$)$ & 2.31 \\
\hline 2006 & 3857487 & 12718 & 32.97 (32.40 to 33.55$)$ & 45.82 (44.88 to 46.78$)$ & 19.69 (19.07 to 20.33$)$ & 2.33 \\
\hline 2007 & 3904068 & 13222 & 33.87 (33.29 to 34.45$)$ & 46.35 (45.41 to 47.31$)$ & 20.99 (20.35 to 21.65$)$ & 2.21 \\
\hline 2008 & 3897624 & 14030 & 36.00 (35.40 to 36.60$)$ & 49.12 (48.15 to 50.11$)$ & 22.46 (21.79 to 23.14$)$ & 2.19 \\
\hline 2009 & 3894989 & 14500 & 37.23 (36.60 to 37.81$)$ & 50.68 (49.69 to 51.68$)$ & 23.35 (22.68 to 24.05 ) & 2.17 \\
\hline 2010 & 3842773 & 14166 & 36.86 (36.26 to 37.48$)$ & 49.75 (48.76 to 50.75$)$ & 23.57 (22.88 to 24.27$)$ & 2.11 \\
\hline 2011 & 3769676 & 13529 & 35.89 (35.29 to 36.50$)$ & 47.98 (47.00 to 48.97$)$ & 23.36 (22.67 to 24.07$)$ & 2.05 \\
\hline 2012 & 3714877 & 13388 & 36.04 (35.43 to 36.66$)$ & 47.57 (46.59 to 48.56$)$ & 24.05 (23.35 to 24.78 ) & 1.98 \\
\hline 2013 & 3473094 & 12532 & 36.08 (35.45 to 36.72 ) & 47.19 (46.18 to 48.21$)$ & 24.49 (23.75 to 25.25$)$ & 1.93 \\
\hline
\end{tabular}

supplementary figures 1 and 2 further illustrate the crude prevalence of CTS over time by age and gender. The prevalence of CTS appears to increase with age in the male population, whereas the prevalence in women peaks in the 50-59 years age group, dips in the 60-69 years age group and then peaks once more in the $70+$ yearsage group.

\section{Trends in incidence}

Table 5 presents the annual incidence (crude estimates) for patients presenting in UK primary care with carpal tunnel syndrome between 1993 and 2013 and the demographics of the population. The denominator population for incidence, which is dependent on patients having 2 years up to standard data prior to the mid-point of the year in question, increased from 783330 person-years in 1993 to 3015670 person-years in 2013. The crude incidence in 1993 was 20.22 per 10000 person-years (95\% CI 19.24 to 21.24), and for 2013, 27.68 per 10000 personyears (95\% CI 27.09 to 28.28). As shown in figure 2 and table 6 , the results of the best fitting Joinpoint regression suggest the incidence increased between 1993 and 2000 ( $\mathrm{APC}=0.3,95 \% \mathrm{CI}-2.3$ to 2.9 ). It then increased more quickly between 2000 and 2004 ( $\mathrm{APC}=6.9,95 \%$ CI 0.5 to 13.7), before slowing between 2004 and 2013 (APC=0.7 $95 \% \mathrm{CI}-0.2$ to 1.6$)$. The female-to-male ratio reduced over time from 2.57 in 1993 to 1.88 in 2013. The median age of female and male patients were noted to increase from 50 and 51 years, respectively in 1993 to 55 and 59 years, respectively in 2013 (see online supplementary table 4 ). See online supplementary table 5 and supplementary figures 3 and 4 further illustrate the incidence of CTS over time by age and gender. As with prevalence, the incidence of CTS appears to increase with age in the male population, whereas the prevalence in women peaks in the 50-59 years age group, dip in the 60-69 years age group and then peak once more in the $70+$ yearsage group.

Trends in the percentage of patients with carpal tunnel syndrome receiving surgical management

Table 7 presents the percentage of prevalent patients with a recorded episode of CTR in each calendar year between 1993 and 2013 and the demographics of this sample. The percentage of all patients with a recorded episode of CTR in 1993 was $19.35 \%$, and for 2013, 27.41\%. As shown in figure 3 and corresponding table 8 , the percentage of patients with a coded episode of CTR increased between 1993 and 2007 ( $\mathrm{APC}=2.6,95 \% \mathrm{CI} 1.9$ to 3.2). It then appeared to decrease between 2007 and 2013 (APC $=-1.7$, $95 \% \mathrm{CI}-3.3$ to -0.3$)$. The median age of females and males receiving CTR were noted to increase from 53 and 

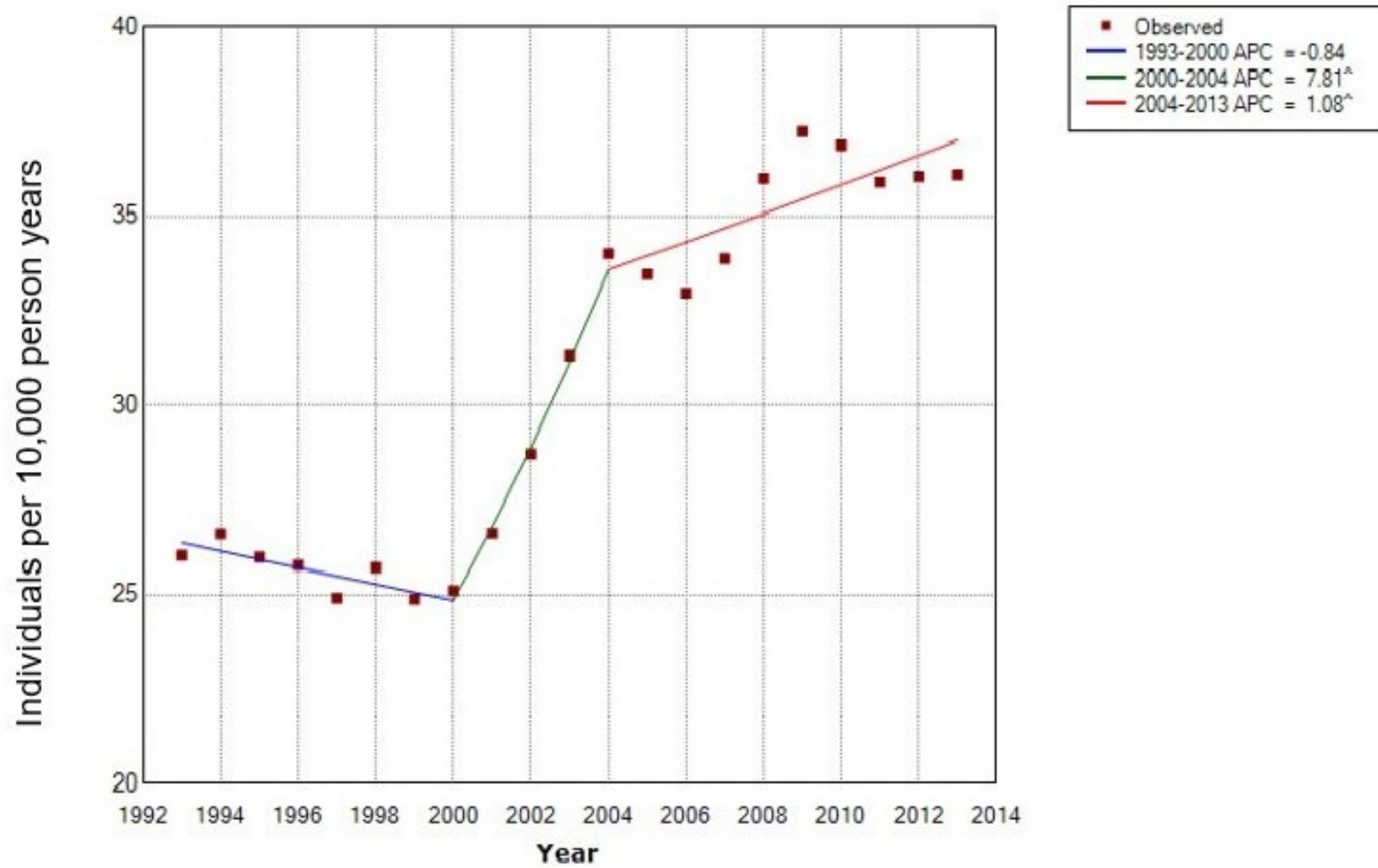

Figure 1 Joinpoint analysis of the crude prevalence of carpal tunnel syndrome between 1993 and 2013 . ^, reflects significance at the 0.05 level; APC, annual percentage change.

55 years, respectively in 1993 to 57 and 62 years, respectively in 2013.

\section{DISCUSSION}

While the prevalence and incidence of CTS have increased over the study period 1993-2013, results show that episodes of surgery, increased until 2007 and declined thereafter.

Online supplementary tables 6 and 7 summarise estimates of the prevalence, incidence and sex ratios of CTS from a previous scoping review of literature pertaining to the general population, demonstrating the substantial variation in results between studies, which may partly be the results of differences in definition of CTS applied and population observed. Studies which also used primary care data showed a similar estimate of the incidence of CTS in a UK primary care population ${ }^{18}$ and similarly reported an increase in incidence over time, although in a Dutch primary care population. ${ }^{21}$ As described in previous studies, CTS shows a peak in prevalence and incidence in women of middle age (50-59 years age group, likely due to hormonal changes around the time of the menopause) ${ }^{18}$ while in the male population, the prevalence and incidence of CTS increased with age. Gelfman et al also commented that an increasing number of older people presenting with CTS had been noted over the course of their study. ${ }^{20}$ The increase in the prevalence and incidence of CTS in the older-aged male groups, may partially account for the observed decrease in the femaleto-male ratio, over time.

The variability in the case definition of CTS was highlighted by Descatha et $a l^{33}$ who identified seven case definitions of CTS proposed for use in population-based studies. Definitions included variations of symptoms

Table 4 Joinpoint analysis of crude prevalence

\begin{tabular}{|c|c|c|c|c|c|c|c|}
\hline Segment & $\begin{array}{l}\text { Lower } \\
\text { end point }\end{array}$ & $\begin{array}{l}\text { Upper } \\
\text { end point }\end{array}$ & $\begin{array}{l}\text { Annual } \\
\text { percentage } \\
\text { change }\end{array}$ & Lower 95th Cl & Upper 95th Cl & $\begin{array}{l}\text { Test } \\
\text { statistic (t) }\end{array}$ & Prob $>\mid \mathbf{t}$ \\
\hline 1 & 1993 & 2000 & -0.8 & -2.6 & 1.0 & -1.0 & 0.3 \\
\hline 2 & 2000 & 2004 & $7.8^{\star}$ & 3.1 & 12.7 & 3.7 & 0.0 \\
\hline 3 & 2004 & 2013 & $1.1^{*}$ & 0.4 & 1.8 & 3.4 & 0.0 \\
\hline
\end{tabular}

${ }^{*}$ Reflects significance at the 0.05 level. 
Table 5 Crude incidence of carpal tunnel syndrome ( $\mathrm{n} / 10000$ person-years) per calendar year, as presented in UK primary care (Clinical Practice Research Datalink)

\begin{tabular}{|c|c|c|c|c|c|c|}
\hline Year & $\begin{array}{l}\text { Number } \\
\text { of person- } \\
\text { years }\end{array}$ & $\begin{array}{l}\text { Incident } \\
\text { individuals }\end{array}$ & $\begin{array}{l}\text { Total crude incidence per } \\
10000 \text { person-years } \\
(95 \% \mathrm{Cl})\end{array}$ & $\begin{array}{l}\text { Female incidence per } \\
10000 \text { person-years } \\
(95 \% \mathrm{Cl})\end{array}$ & $\begin{array}{l}\text { Male incidence per } \\
10000 \text { person-years } \\
(95 \% \mathrm{Cl})\end{array}$ & Female:male \\
\hline 1993 & 783330 & 1584 & 20.22 (19.24 to 21.24$)$ & 28.72 (27.09 to 30.42 ) & 11.17 (10.14 to 12.29$)$ & 2.57 \\
\hline 1994 & 868616 & 1797 & 20.69 (19.74 to 21.67$)$ & 28.52 (26.97 to 30.13$)$ & 12.38 (11.34 to 13.69$)$ & 2.30 \\
\hline 1995 & 1003593 & 1963 & 19.56 (18.70 to 20.45$)$ & 27.53 (26.12 to 29.00$)$ & 11.12 (10.20 to 12.10$)$ & 2.48 \\
\hline 1996 & 1065068 & 2142 & 20.11 (19.27 to 20.98 ) & 28.39 (27.00 to 29.84$)$ & 11.37 (10.47 to 12.33$)$ & 2.50 \\
\hline 1997 & 1150299 & 2306 & 20.05 (19.24 to 20.88 ) & 28.39 (27.05 to 29.79 ) & 11.25 (10.39 to 12.16$)$ & 2.52 \\
\hline 1998 & 1300074 & 2696 & 20.74 (19.95 to 21.52$)$ & 29.65 (28.57 to 31.22$)$ & 11.37 (10.56 to 12.23$)$ & 2.61 \\
\hline 1999 & 1497673 & 3030 & 20.23 (19.52 to 20.10$)$ & 28.53 (27.35 to 29.75$)$ & 11.54 (10.77 to 12.34$)$ & 2.47 \\
\hline 2000 & 1682027 & 3462 & 20.58 (19.90 to 21.28$)$ & 28.66 (27.54 to 29.81$)$ & 12.15 (11.41 to 12.93$)$ & 2.36 \\
\hline 2001 & 2019596 & 4391 & 21.74 (21.10 to 22.40$)$ & 29.72 (28.68 to 30.79$)$ & 13.46 (12.74 to 14.20$)$ & 2.21 \\
\hline 2002 & 2456761 & 5718 & 23.27 (22.68 to 31.78 ) & 31.78 (30.78 to 32.79$)$ & 14.47 (13.80 to 15.17$)$ & 2.20 \\
\hline 2003 & 2669111 & 6772 & 25.37 (24.77 to 25.98$)$ & 35.13 (34.14 to 36.14$)$ & 15.33 (14.67 to 16.02$)$ & 2.29 \\
\hline 2004 & 2779821 & 7868 & 28.30 (27.68 to 28.94$)$ & 39.22 (38.19 to 40.27$)$ & $17.10(16.42$ to 17.81$)$ & 2.29 \\
\hline 2005 & 3164506 & 8113 & 25.64 (25.08 to 26.20$)$ & 35.55 (34.63 to 36.48$)$ & 15.49 (14.88 to 16.12$)$ & 2.30 \\
\hline 2006 & 3307051 & 8337 & 25.21 (24.67 to 25.76 ) & 34.91 (34.02 to 35.82$)$ & 15.27 (14.68 to 15.89$)$ & 2.29 \\
\hline 2007 & 3343009 & 8865 & 26.52 (25.97 to 27.08$)$ & 35.76 (34.86 to 36.67$)$ & 17.07 (16.45 to 17.71$)$ & 2.09 \\
\hline 2008 & 3341299 & 9437 & 28.24 (27.68 to 28.82 ) & 38.23 (37.30 to 39.17$)$ & 18.06 (17.42 to 18.72$)$ & 2.12 \\
\hline 2009 & 3383196 & 9918 & 29.32 (28.74 to 29.90$)$ & 39.73 (38.79 to 50.68$)$ & 18.69 (18.04 to 19.36$)$ & 2.13 \\
\hline 2010 & 3357338 & 9634 & 28.70 (28.13 to 29.27$)$ & 38.70 (37.77 to 39.64$)$ & 18.46 (17.82 to 19.13$)$ & 2.10 \\
\hline 2011 & 3269296 & 9083 & 27.78 (27.21 to 28.36$)$ & 37.11 (36.19 to 38.05$)$ & 18.20 (17.54 to 18.87$)$ & 2.04 \\
\hline 2012 & 3222880 & 9011 & 27.96 (27.39 to 28.54$)$ & 36.44 (35.52 to 37.88$)$ & 19.23 (18.56 to 19.93$)$ & 1.89 \\
\hline 2013 & 3015670 & 8346 & 27.68 (27.09 to 28.28 ) & 35.95 (35.01 to 36.92 ) & 19.12 (18.43 to 19.84$)$ & 1.88 \\
\hline
\end{tabular}

only; symptoms and examination findings; symptoms and either physical examination or electrodiagnostic results and symptoms and electrodiagnostic results. This study showed a range in the population prevalence of CTS from $2.5 \%$ to $11 \%$, with studies using less specific case definitions yielding higher prevalence rates. ${ }^{33}$ Misclassification ranged between $1 \%$ and $10 \%$. The prevalence of CTS in any given population is likely therefore to depend on the definition of CTS applied. The case definition in our study is derived from general practitioner (GP)-recorded diagnosis and treatment codes, which may have been based on clinical findings alone; those who have had further investigations and those who have received definitive condition-specific treatment. Hence, it uses a pragmatic approach, across a large population that will include all patients presenting to their GP with symptoms. Our study methods do however assume that patients with symptoms will be presenting in primary care or be receiving definitive coded treatment. The study will not capture patients with chronic symptoms who are not presenting in primary care or who had a coded episode of surgery or injection.

Although Joinpoint analysis does not provide evidence for the cause of a change in observed outcomes, it highlights when a significant change in trend has taken place.
Our results suggest that the annual percentage change in prevalence and incidence was highest between 2000 and 2004. A possible reason for this may be the publication of the UK Government's information technology strategy for the NHS in $1998,{ }^{34}$ which proposed that by 2005, the person-based electronic health record (HER), would have been fully implemented. ${ }^{35}$ Although no direct evidence for this was found, it may be possible that with the increasing use of IT systems in primary care and attention to providing Read codes for each consultation, episodes of CTS were more frequently and accurately recorded. This would not however explain the continuing increase of the incidence in CTS post-2005.

Between 2000 and 2004, the Government implemented the second phase of its 'War on Waiting', that is, the reduction of waiting times. For example, the maximum wait for a day-case procedure (eg, a CTR) was reduced from 18 months to 6 months. ${ }^{36}$ The peak in prevalence of CTS (with our definition partly based also on treatment codes, which in 2013 constituted $29.36 \%$ of prevalent patients) observed in 2004 may therefore be partly explained by the fact that patients requiring surgery were 'accumulating' between 2000 and 2004 and subsequently received definitive treatment. This effect would however not be expected to impact so heavily on the incidence, which 

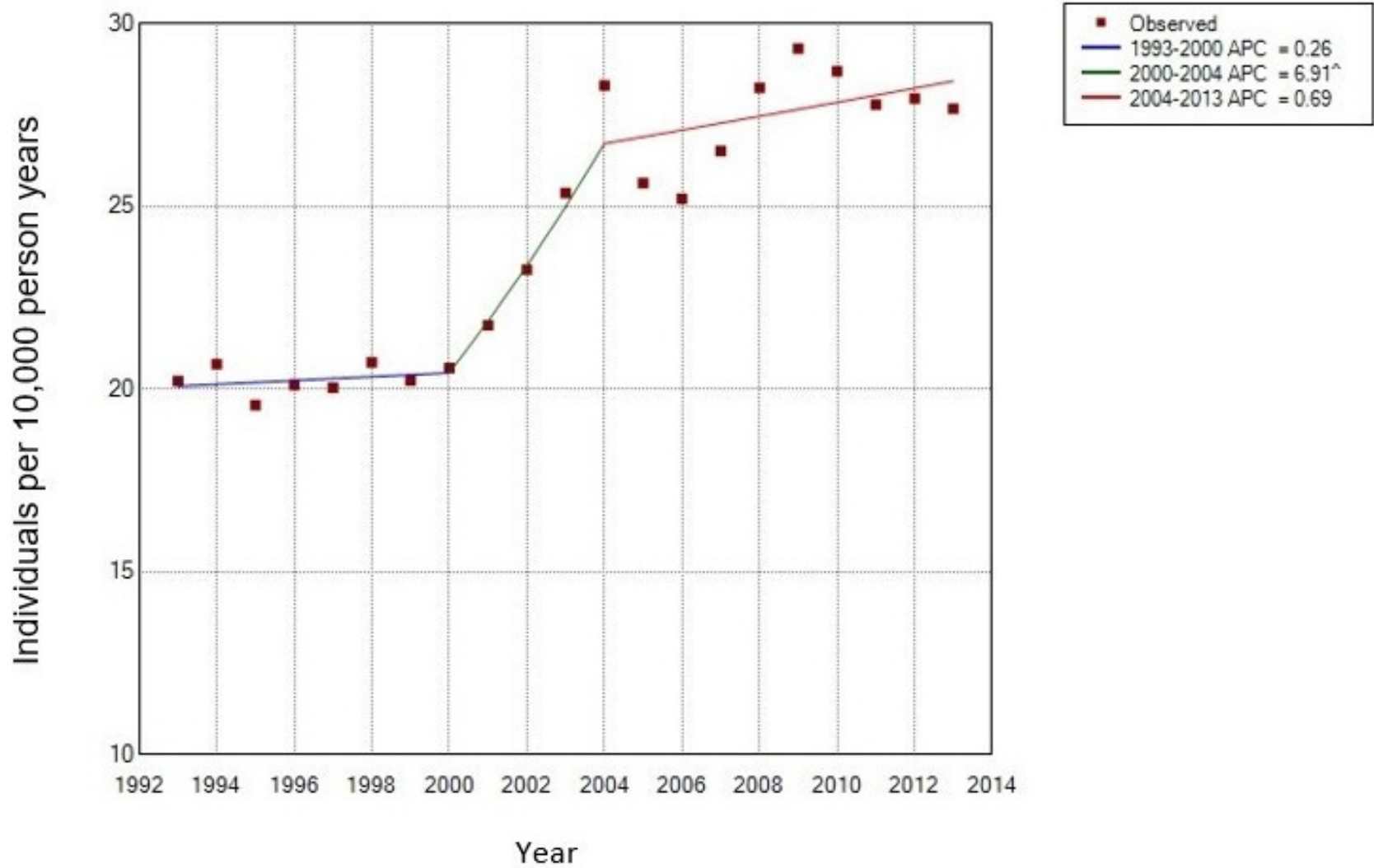

Figure 2 Joinpoint analysis of the crude incidence of carpal tunnel syndrome between 1993 and $2013 . \wedge$, reflects significance at the 0.05 level; APC, annual percentage change.

disregards repeat patient presentations in subsequent annual periods, unless patients with a less specific code received treatment and appeared as an incident case. The introduction of the 18-week target of time from referral to treatment in 2008 did not seem to have a similar impact on estimates of prevalence or incidence of CTS, which makes it less certain to what extent these policy changes may have influenced our results. There are likely to be further reasons behind the observed changes.

The change in trends of 2004 may also represent a change in service. The introduction of the Quality and Outcome Framework (QOF) occurred with the advent of the General Medical Services contract in 2004. Although there has never been a musculoskeletal health domain, the importance of coding to maintain registers and evidence of outcomes in line with QOF may have influenced coding behaviour.
At the same time as QOF, Primary Care Trusts (PCTs) were given a role in commissioning services. The ability of PCTs to commission new services heralded the development of the Musculoskeletal Interface Clinics (MIC), which act as a 'one stop shop' for patients with musculoskeletal problems. A referral to this clinic from primary care may also be a reason prevalent patients with persisting symptoms stopped presenting in primary care.

These three factors (improved coding, service redevelopment and a reduction in waiting times) may all partly explain the change in incidence and prevalence of CTS between 2000 and 2004 but are unlikely to fully explain the observed trends. Further factors of potential influence may include the increasing rates of risk factors of CTS such as diabetes and obesity. ${ }^{37}{ }^{38}$ While standardising the prevalence and incidence by age and gender did not change the overall picture of the changing trends, online

Table 6 Joinpoint analysis of crude incidence

\begin{tabular}{|c|c|c|c|c|c|c|c|}
\hline Segment & $\begin{array}{l}\text { Lower } \\
\text { end point }\end{array}$ & $\begin{array}{l}\text { Upper } \\
\text { end point }\end{array}$ & $\begin{array}{l}\text { Annual } \\
\text { percentage } \\
\text { change }\end{array}$ & Lower 95th Cl & Upper 95th Cl & $\begin{array}{l}\text { Test } \\
\text { statistic (t) }\end{array}$ & Prob $>|t|$ \\
\hline 1 & 1993 & 2000 & 0.3 & -2.3 & 2.9 & 0.2 & 0.8 \\
\hline 2 & 2000 & 2004 & $6.9^{\star}$ & 0.5 & 13.7 & 2.3 & 0.0 \\
\hline 3 & 2004 & 2013 & 0.7 & -0.2 & 1.6 & 1.7 & 0.1 \\
\hline
\end{tabular}

${ }^{*}$ Reflects significance at the 0.05 level. 
Table 7 Percentage of patients with carpal tunnel syndrome with a recorded episode of carpal tunnel release surgery per calendar year, as presented in UK primary care (Clinical Practice Research Datalink)

\begin{tabular}{|c|c|c|c|c|c|c|}
\hline Year & $\begin{array}{l}\text { Episodes per } \\
10000 \text { person- } \\
\text { years }\end{array}$ & $\begin{array}{l}\% \text { prevalent } \\
\text { individuals having } \\
\text { surgery }\end{array}$ & $\begin{array}{l}\% \text { prevalent } \\
\text { females having } \\
\text { surgery }\end{array}$ & $\begin{array}{l}\% \text { prevalent } \\
\text { males having } \\
\text { surgery }\end{array}$ & $\begin{array}{l}\text { Female median } \\
\text { age }(25 \%-75 \% \text { IOR })\end{array}$ & $\begin{array}{l}\text { Male median } \\
\text { age }(25 \%-75 \% \text { IQR) }\end{array}$ \\
\hline 1993 & 5.04 & 19.35 & 18.78 & 21.03 & $53(43-64)$ & 55 (44-69) \\
\hline 1994 & 5.70 & 21.42 & 20.62 & 23.52 & $53(43-68)$ & $58(45-70)$ \\
\hline 1995 & 6.19 & 23.81 & 23.40 & 24.92 & $53(42-67)$ & $55(44-70)$ \\
\hline 1996 & 5.41 & 20.99 & 20.48 & 22.43 & $53(44-65)$ & $52(40-65)$ \\
\hline 1997 & 5.70 & 22.89 & 22.14 & 24.81 & $53(45-67)$ & $56(42-69)$ \\
\hline 1998 & 5.73 & 22.28 & 21.28 & 25.00 & $53(44-65)$ & $53(44-65)$ \\
\hline 1999 & 6.24 & 25.09 & 24.60 & 26.38 & $54(44-67)$ & $56(46-70)$ \\
\hline 2000 & 6.41 & 25.54 & 24.84 & 27.23 & $54(44-68)$ & 56 (45-69) \\
\hline 2001 & 6.88 & 25.87 & 25.95 & 25.68 & $55(45-68)$ & $58(46-71)$ \\
\hline 2002 & 7.02 & 24.46 & 24.19 & 25.09 & $57(46-71)$ & $55(45-68)$ \\
\hline 2003 & 8.26 & 26.39 & 25.88 & 27.66 & $56(45-67)$ & $57(46-71)$ \\
\hline 2004 & 9.34 & 27.48 & 27.38 & 27.74 & $56(46-67)$ & $57(47-68)$ \\
\hline 2005 & 9.70 & 29.00 & 28.31 & 30.65 & $57(47-68)$ & $58(46-71)$ \\
\hline 2006 & 9.36 & 28.40 & 28.31 & 28.61 & $57(47-68)$ & $60(48-72)$ \\
\hline 2007 & 9.71 & 28.66 & 28.26 & 29.59 & $56(46-69)$ & $59(48-71)$ \\
\hline 2008 & 10.53 & 29.25 & 29.00 & 29.82 & $56(46-68)$ & $60(49-72)$ \\
\hline 2009 & 10.92 & 29.32 & 28.73 & 30.66 & $56(46-70)$ & $61(49-72)$ \\
\hline 2010 & 10.40 & 28.22 & 27.57 & 29.62 & 57 (47-71) & $61(48-73)$ \\
\hline 2011 & 9.47 & 26.37 & 26.11 & 26.93 & $57(47-70)$ & $61(49-73)$ \\
\hline 2012 & 9.48 & 26.31 & 25.89 & 27.19 & $57(47-71)$ & $60(49-73)$ \\
\hline 2013 & 9.89 & 27.41 & 26.47 & 29.30 & $57(48-70)$ & $62(51-74)$ \\
\hline
\end{tabular}

supplementary figure 1 suggests that the prevalence of CTS increased most obviously in the male and female over 70 years age groups.

The Joinpoint analysis suggested an increase in surgical management of CTS between 1993 and 2007 (APC=2.55), followed by a reducing trend between 2007 (95\% CI 2004 to 2009) and the end of the study in $2013(\mathrm{APC}=-1.72)$.

Previous studies have described the epidemiology and the rates of CTR in the UK. This study provides updated data observing the presenting primary care population. Using data from the General Practice Research Database (GPRD) (forerunner to CPRD), Latinovic et al reported that $31 \%$ of patients with CTS had surgery in $2000,{ }^{18}$ which is similar to the $25.5 \%$ found in our study at the same time point. The small difference between the estimates may be the result of a difference in the calculation used to derive the denominator population. Audit data from one tertiary hand centre, Wildin $e t$ al also showed that the rate of referrals for CTR surgery had increased over the 10 years between 1989-1999 and 2000-2001. ${ }^{25}$ Furthermore, Bebbington and Furniss observed demographic population shifts in hand conditions including CTS within HES, which record diagnoses and procedures performed within the National Health Service (NHS) Hospitals in England. They used linear regression to predict future trends in hand surgery, showing that while absolute numbers of CTS diagnoses and CTR procedures increased between 1998 and 2011, the pre-2008 increase in CTR was significantly steeper than the post-2008 slope $(p<0.001) .{ }^{26}$ This is suggestive of a decrease in the surgical management of CTS in terms of the proportion of patients with CTS having an operation, but not necessarily in the numbers of surgical episodes in absolute terms, which Bebbington and Furniss predict will have increased by $99 \%$ (95\% CI 65 to 132) in 2030 compared with 2011. ${ }^{26}$ The data from CPRD however, suggested a reduction in both real-term episodes of CTR as well as the proportion of the (increasing) prevalent population receiving surgical treatment.

We may speculate regarding potential reasons for the initial increase in surgical management of CTS, for example, increased access to specialist services (eg, community-based MIC), increased litigation leading to more definitive treatments being sought and increased patient expectations and demand, but we have no evidence for such explanations.

The decreasing trend in the use of CTR post-2007 is likely to be multifactorial; however, the changing structure of the NHS and its funding streams may have influenced the observed trend. Around 2007-2008, practice-based 

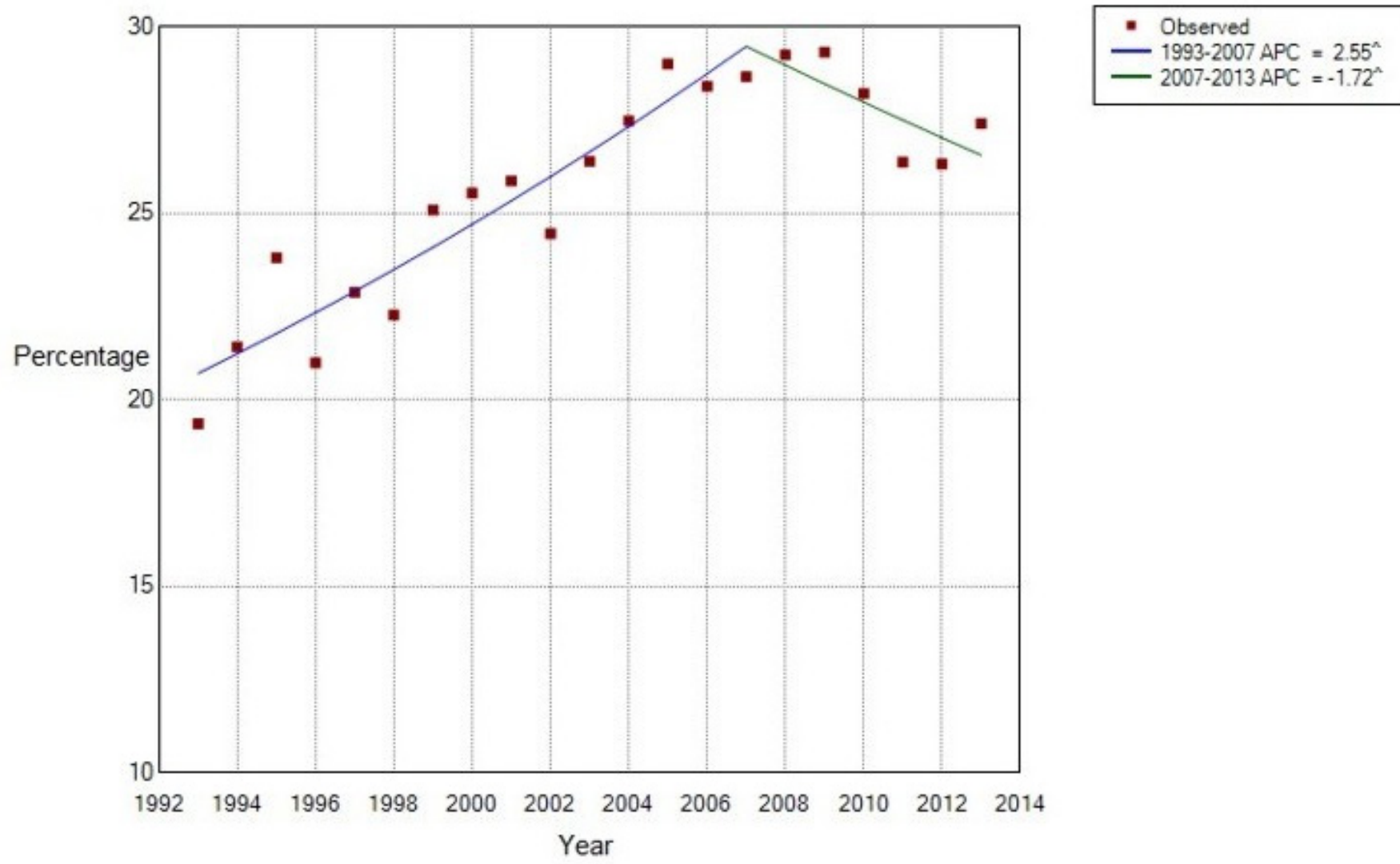

Figure 3 Joinpoint analysis of the percentage of prevalent patients with a recorded episode of carpal tunnel release, in each calendar year syndrome, between 1993 and 2013. ^, reflects significance at the 0.05 level; APC, annual percentage change.

commissioning was being introduced. This gave primary care notional budgets with which to purchase care for their patients with the aim of aligning clinical and financial responsibility. Restricting access to certain procedures including CTR, by implementing prespecified criteria, was one way to help achieve this, which may have resulted in a reduction in the use of CTR.

There are a number of limitations associated with the data in this study. The accuracy of consultation data is dependent on the validity of the computerised information it uses. In a review of 212 publications which aimed to validate diagnoses recorded in GPRD data, Herrett et al reported that the median proportion of cases with a confirmed diagnosis was $89 \%$ (range 24\%-100\%), but the majority of publications did not present the sensitivity of a coded diagnosis, which means that information regarding the proportion of missed cases is lacking. Potential misclassification; non-attendance in primary care; variation in between GP coding and a lack of coding may all lead to an unmeasured shortfall in observed cases. ${ }^{27}{ }^{39}$ This study relies on the diagnosis of CTS to be correct and the subsequent coding to be precise. While CTS diagnoses have not been validated, in a study comparing musculoskeletal diagnoses in four different databases, Jordan et al suggested that musculoskeletal coding in GPRD was less reliable than in its other healthcare datasets including CiPCA. ${ }^{40}$ We took measures to reduce the effect of miscoding (eg, including surgery and injection codes in prevalence measures, if diagnostic codes had not been used), but it is possible that results will not be entirely representative of the true prevalence and incidence of CTS.

Given the lack of clarity in the accuracy of coding and the likelihood that associated clinical encounters following a CTR were coded using a surgical code, only the first surgical code could reliably be used to indicate an

Table 8 Joinpoint analysis of the use of surgery

\begin{tabular}{llllcccl}
\hline Segment & $\begin{array}{l}\text { Lower } \\
\text { end point }\end{array}$ & $\begin{array}{l}\text { Upper } \\
\text { end point }\end{array}$ & $\begin{array}{l}\text { Annual } \\
\text { percentage } \\
\text { change }\end{array}$ & Lower 95th Cl Upper 95thCl & $\begin{array}{l}\text { Test statistic } \\
\text { (t) }\end{array}$ & Prob > |t| \\
\hline 1 & 1993 & 2007 & $2.6^{*}$ & 1.9 & 3.2 & 8.2 & 0.0 \\
2 & 2007 & 2013 & $-1.7^{*}$ & -3.1 & -0.3 & -2.6 & 0.0 \\
\hline
\end{tabular}

${ }^{*}$ Reflects significance at the 0.05 level. 
episode of surgery. This is likely to have led to an underestimation of surgical episodes being identified as episodes on the contralateral hand will have been automatically discounted as they were undistinguishable. Furthermore, prevalence and incidence were similarly likely to have been underestimated as repeat presentations for the ipsilateral hand are indistinguishable from presentations in the contralateral hand.

While CPRD provides a large generalisable sample, which has substantial benefits when estimating epidemiological trends, it cannot directly measure patient-reported outcomes. Furthermore, surgery can be seen as a 'gold standard' treatment, but it does not necessarily signify cure. A review of the surgical treatment of CTS reported that $70 \%-90 \%$ of patients undergoing a CTR have a good outcome (definitions varied). ${ }^{41}$ In a retrospective cohort study over a mean follow-up of 13 years postsurgery, $88 \%$ of patients were either completely satisfied or very satisfied with surgery. Seventy-four per cent reported their symptoms had completely resolved; $1.8 \%$ (113 patients) had undergone repeat surgery. ${ }^{42}$ There is little evidence however that CTR is an appropriate initial management option for patients presenting to primary care with mild-to-moderate symptoms, especially in the absence of high-quality trial evidence that conservative management is ineffective. ${ }^{4344}$

Future research in this field could describe the characteristics of patients presenting with CTS in greater detail, and observe course and prognosis of CTS in primary care. It may then be possible to identify predictors of the outcome of primary care management, and potentially identify patients requiring surgery.

\section{CONCLUSION}

An increase in the incidence and prevalence of CTS is likely to lead to an increased demand on services and cost to the healthcare economy. ${ }^{26}$ This study has demonstrated an increase in the prevalence and incidence of physician diagnosed CTS over the study period between 1993 and 2013. Rates of referral for CTS and surgical intervention have also increased over the study period; however in the later years of the study, the per cent of patients receiving surgery has begun to decline .

Acknowledgements The authors wish to thank Dr Dahai Yu for his assistance with the CPRD data download.

Contributors $\mathrm{CB}, \mathrm{LC}, \mathrm{YC}$ and $\mathrm{DAvdW}$ contributed to the initial draft and subsequent revisions. $\mathrm{CB}$ is the guarantor of the paper. All authors had full access to all of the data and can take responsibility for the integrity of the data and the accuracy of the data analysis. CB affirms that the manuscript is an honest, accurate and transparent account of the study being reported; that no important aspects of the study have been omitted and that any discrepancies from the study as planned have been explained.

Funding CB is funded by the National Institute of Health Research School for Primary Care (NIHR SPCR). DAvdW is a member of PROGRESS Medical Research Council Prognosis Research Strategy (PROGRESS) Partnership (G0902393/99558).

Disclaimer The views expressed are those of the authors and not necessarily those of the NIHR, the NHS or the Department of health. No other relationships or activities that could appear to have influenced the submitted work.
Competing interests None declared.

Patient consent Not required.

Provenance and peer review Not commissioned; externally peer reviewed.

Data sharing statement To ensure patient privacy and confidentiality, data from the CPRD cannot be shared. Therefore, no additional data are available.

Open access This is an open access article distributed in accordance with the terms of the Creative Commons Attribution (CC BY 4.0) license, which permits others to distribute, remix, adapt and build upon this work, for commercial use, provided the original work is properly cited. See: http://creativecommons.org/ licenses/by/4.0/

(c) Article author(s) (or their employer(s) unless otherwise stated in the text of the article) 2018. All rights reserved. No commercial use is permitted unless otherwise expressly granted.

\section{REFERENCES}

1. Alfonso C, Jann S, Massa R, et al. Diagnosis, treatment and follow-up of the carpal tunnel syndrome: a review. Neurol Sci 2010;31:243-52.

2. Aroori S, Spence RA. Carpal tunnel syndrome. Ulster Med J 2008;77:6-17.

3. Padua L, Padua R, Lo Monaco M, et al. Multiperspective assessment of carpal tunnel syndrome: a multicenter study. Italian CTS Study Group. Neurology 1999;53:1654-9.

4. Foley M, Silverstein B, Polissar N. The economic burden of carpal tunnel syndrome: long-term earnings of CTS claimants in Washington State. Am J Ind Med 2007;50:155-72.

5. Atroshi I, Gummesson C, Johnsson R, et al. Symptoms, disability, and quality of life in patients with carpal tunnel syndrome. J Hand Surg Am 1999;24:398-404.

6. Jenkins PJ, Srikantharajah D, Duckworth AD, et al. Carpal tunnel syndrome: the association with occupation at a population level. Journal of Hand Surgery 2013;38:67-72.

7. Middleton SD, Anakwe RE. Carpal tunnel syndrome. BMJ 2014;349:g6437.

8. Padua L, Coraci D, Erra C, et al. Carpal tunnel syndrome: clinical features, diagnosis, and management. Lancet Neurol 2016;15:1273-84.

9. American Academy of Orthopaedic Surgeons. Clinical practice guideline on the diagnosis of carpal tunnel syndrome. 2007.

10. Carpal tunnel syndrome. http://cks.nice.org.uk/carpal-tunnelsyndrome\#!scenariorecommendation:1 (accessed 14 May 2013).

11. Carpal Tunnel Syndrome (CTS) - the map of medicine. http://app. mapofmedicine.com/mom/127/page.html?department-id=8\& specialty-id=1037\&pathway-id=3411\&page-id=8741\&history=clear (accessed 25 Oct 2012).

12. Royal College of Surgeons. Commissioning guide: treatment of carpal tunnel syndrome. 2016.

13. Middleton SD, Anakwe RE. Carpal tunnel syndrome: evidence-based medicine. BMJ 2014;349.

14. Ferry S, Pritchard T, Keenan J, et al. Estimating the prevalence of delayed median nerve conduction in the general population. $\mathrm{Br} J$ Rheumatol 1998;37:630-5.

15. de Krom MC, Knipschild PG, Kester AD, et al. Carpal tunnel syndrome: prevalence in the general population. J Clin Epidemiol 1992;45:373-6.

16. Atroshi I. Carpal tunnel syndrome-prevalence, electrodiagnosis and outcome instruments. Acta Orthop Scand 1999;70:70-1.

17. Papanicolaou GD, McCabe SJ, Firrell J. The prevalence and characteristics of nerve compression symptoms in the general population. J Hand Surg Am 2001;26:460-6.

18. Latinovic R, Gulliford MC, Hughes RA. Incidence of common compressive neuropathies in primary care. J Neurol Neurosurg Psychiatry 2006;77:263-5.

19. Bland JDP, Rudolfer SM. Clinical surveillance of carpal tunnel syndrome in two areas of the United Kingdom, 1991-2001. J Neurol, Neurosurg \& Psyc 2003;74:1674-9.

20. Gelfman R, Melton LJ, Yawn BP, et alLong-term trends in carpal tunnel syndrome. Neurology 2009;72:33-41.

21. Bongers FJ, Schellevis FG, van den Bosch WJ, et al. Carpal tunnel syndrome in general practice (1987 and 2001): incidence and the role of occupational and non-occupational factors. Br J Gen Pract 2007;57:36-9.

22. Atroshi I, Englund M, Turkiewicz A, et al. Incidence of physiciandiagnosed carpal tunnel syndrome in the general population. Arch Intern Med 2011;171:941-5. 
23. Jenkins PJ, Watts AC, Duckworth AD, et al. Socioeconomic deprivation and the epidemiology of carpal tunnel syndrome. J Hand Surg Eur Vol 2012;37:123-9.

24. Nordstrom DL, DeStefano F, Vierkant RA, et al. Incidence of diagnosed carpal tunnel syndrome in a general population. Epidemiology 1998;9:342-5.

25. Wildin C, Dias JJ, Heras-Palou C, et al. Trends in elective hand surgery referrals from primary care. Ann $R$ Coll Surg Engl 2006;88:543-6.

26. Bebbington E, Furniss D. Linear regression analysis of hospital episode statistics predicts a large increase in demand for elective hand surgery in England. J Plast Reconstr Aesthet Surg 2015;68:243-51.

27. Herrett E, Gallagher AM, Bhaskaran K, et al. Data resource profile: Clinical Practice Research Datalink (CPRD). Int J Epidemiol 2015;44:827-36.

28. Chisholm J. The read clinical classification. BMJ 1990;300:1092.

29. Jordan K, Porcheret M, Croft P. Quality of morbidity coding in general practice computerized medical records: a systematic review. Fam Pract 2004;21:396-412.

30. Population estimates. https://www.ons.gov.uk/peoplepopulationandc ommunity/populationandmigration/populationestimates (accessed 16 Feb 2017).

31. National Cancer Institute. Joinpoint Regression Program Surveillance Research Program. 2017.

32. Bedson J, Chen Y, Hayward RA, et al. Trends in long-term opioid prescribing in primary care patients with musculoskeletal conditions: an observational database study. Pain 2016;157:1525-31.

33. Descatha A, Dale AM, Franzblau A, et al. Comparison of research case definitions for carpal tunnel syndrome. Scand J Work Environ Health 2011;37:298-306.
34. NHS Executive. Information for health: an information strategy for the modern NHS 1998-2005. A national strategy for local implementation. 1998.

35. Porcheret M, Hughes R, Evans D, et al. Data quality of general practice electronic health records: the impact of a program of assessments, feedback, and training. J Am Med Inform Assoc 2004; $11: 78-86$

36. Lewis R, Appleby J. Can the english NHS meet the 18-week waiting list target? J R Soc Med 2006;99:10-13.

37. Pourmemari MH, Shiri R. Diabetes as a risk factor for carpal tunnel syndrome: a systematic review and meta-analysis. Diabet Med 2016;33:10-16.

38. Shiri R, Pourmemari MH, Falah-Hassani K, et al. The effect of excess body mass on the risk of carpal tunnel syndrome: a meta-analysis of 58 studies. Obes Rev 2015;16:1094-104.

39. Herrett E, Thomas SL, Schoonen WM, et al. Validation and validity of diagnoses in the General Practice Research Database: a systematic review. Br J Clin Pharmacol 2010;69:4-14.

40. Jordan K, Clarke AM, Symmons DP, et al. Measuring disease prevalence: a comparison of musculoskeletal disease using four general practice consultation databases. Br J Gen Pract 2007;57:7-14.

41. Turner A, Kimble F, Gulyás K, et al. Can the outcome of open carpal tunnel release be predicted?: a review of the literature. ANZ J Surg 2010;80:50-4.

42. Louie DL, Earp BE, Collins JE, et al. Outcomes of open carpal tunnel release at a minimum of ten years. J Bone Joint Surg Am 2013;95:1067-73.

43. Marshall SC, Tardif G, Ashworth NL. Cochrane Neuromuscular Group. Local corticosteroid injection for carpal tunnel syndrome. Cochrane Database Syst Rev 2007;29:001554.

44. Page MJ, Massy-Westropp N, O'Connor D, et al. Splinting for carpal tunnel syndrome. Cochrane Database Syst Rev 2012:CD010003. 